\title{
Simultaneous Analysis of Losartan Potassium, Amlodipine Besylate, and Hydrochlorothiazide in Bulk and in Tablets by High-Performance Thin Layer Chromatography with UV-Absorption Densitometry
}

\author{
Karunanidhi Santhana Lakshmi and Sivasubramanian Lakshmi \\ Department of Pharmaceutical Analysis, SRM College of Pharmacy, SRM University, Tamilnadu, \\ Kattankulathur 603 203, India \\ Correspondence should be addressed to Sivasubramanian Lakshmi, lakshmiss@hotmail.com
}

Received 22 November 2011; Accepted 23 January 2012

Academic Editor: Peter Stockwell

Copyright (C) 2012 K. Santhana Lakshmi and S. Lakshmi. This is an open access article distributed under the Creative Commons Attribution License, which permits unrestricted use, distribution, and reproduction in any medium, provided the original work is properly cited.

A Simple high-performance thin layer chromatography (HPTLC) method for separation and quantitative analysis of losartan potassium, amlodipine, and hydrochlorothiazide in bulk and in pharmaceutical formulations has been established and validated. After extraction with methanol, sample and standard solutions were applied to silica gel plates and developed with chloroform : methanol : acetone : formic acid 7.5: $1.3: 0.5: 0.03(v / v / v / v)$ as mobile phase. Zones were scanned densitometrically at $254 \mathrm{~nm}$. The $R_{f}$ values of amlodipine besylate, hydrochlorothiazide, and losartan potassium were $0.35,0.57$, and 0.74 , respectively. Calibration plots were linear in the ranges 500-3000 ng per spot for losartan potassium, amlodipine and hydrochlorothiazide, the correlation coefficients, $r$, were $0.998,0.998$, and 0.999 , respectively. The suitability of this method for quantitative determination of these compounds was by validation in accordance with the requirements of pharmaceutical regulatory standards. The method can be used for routine analysis of these drugs in bulk and in formulation.

\section{Introduction}

Losartan (LOS), 2-n-butyl-4-chloro-5-hydroxy methyl-1-[2' (1H-tetrazol-5-yl) (biphenyl-4-yl) methyl] imidazole, potassium is a strong nonpeptide antihypertensive agent which exerts its action by specific blocking of angiotensin II receptors [1]. It has a gradual long-lasting effect as an antihypertensive. Amlodipine (AML), 3-ethyl 5-methyl (RS) 2(2-aminoethoxymethyl)-4-(2-Chlorophenyl)-6-methyl-

dihydropyridine-3,5-dicarboxylate is a calcium channel blocker which inhibits the influx of extracellular calcium across the myocardial and vascular muscle cell membranes [2]. Hydrochlorothiazide (HCZ), 6-chloro-3,4-dihydro-2H1,2,4-benzothiadiazine-7-sulphonamide 1,1-dioxide, which is widely used in antihypertensive pharmaceutical preparations reduces active sodium reabsorption and peripheral vascular resistance [1-3].
A literature survey reveals that a variety of spectrophotometric and chromatographic methods, including UV derivative, the simultaneous equation method, colorimetric determination, HPLC, ratio derivative and compensation technique, and a stability indicating HPLC method, have been reported for the determination of LOS in pharmaceutical dosage forms in combination with other drugs [4-14]. Spectrophotometric and chromatographic methods have been reported for determination of AML, in combination with other drugs, in bulk and pharmaceutical dosage forms [15-24]. A variety of methods have been used for the determination of hydrochlorothiazide [25-34]. No method has been reported for the simultaneous estimation of LOS, AML, and HCZ in the combined dosage form.

In recent years TLC has been improved to incorporate HPTLC-grade stationary phases, automated sampleapplication devices, a controlled development environment, 
TABLE 1: Results from assay of losartan potassium, amlodipine besylate, and hydrochlorothiazide in Trilopace* $\mathrm{H}$ tablets.

\begin{tabular}{lccc}
\hline Component & $\begin{array}{c}\text { Label } \\
\text { claim } \\
(\mathrm{mg})\end{array}$ & $\begin{array}{c}\text { Amount found } \\
(\mathrm{mg} \pm \mathrm{SD}, \\
n=3)\end{array}$ & $\begin{array}{c}\text { Percentage of } \\
\text { label claim } \\
( \pm \mathrm{SD})\end{array}$ \\
\hline Losartan potassium & 50 & $49.51 \pm 0.330$ & $99.03 \pm 0.665$ \\
Amlodipine besylate & 5 & $4.86 \pm 0.057$ & $98.47 \pm 1.114$ \\
Hydrochlorothiazide & 12.5 & $12.4 \pm 0.036$ & $99.22 \pm 0.284$ \\
\hline
\end{tabular}

automated development, forced-flow techniques, computercontrolled densitometry, quantitation, and fully validated procedures. These features result in methods which are not only convenient, rapid, robust, and cost effective but also reproducible, accurate, and reliable. The objective of this investigation was, therefore, to establish an HPTLC method for simultaneous estimation of LOS, AML, and HCZ in bulk and in tablets.

\section{Experimental}

2.1. Materials and Reagents. Analytically pure samples of losartan potassium, hydrochlorothiazide, and amlodipine besylate were procured from Madras Pharmaceuticals, Chennai, as gift samples and used as working standards, methanol of HPLC grade from Merck (Mumbai, India), and chloroform, acetone, and formic acid of analytical reagent grade from S.D. Fine Chemicals were used, without purification to prepare the mobile phase.

A solution containing $1 \mathrm{mg} / \mathrm{mL}$ losartan potassium, amlodipine besylate, and hydrochlorothiazide was prepared by dissolving $10 \mathrm{mg}$ of each standard in $10 \mathrm{~mL}$ methanol and was used as working standard solution.

2.2. Sample Preparation. Twenty TRILOPACE* tablets by Akums Drugs \& Pharmaceuticals Ltd containing $50 \mathrm{mg}$ losartan potassium, $5 \mathrm{mg}$ amlodipine besylate, and $12.5 \mathrm{mg}$ hydrochlorothiazide were weighed and powdered. An amount of powder equivalent to $50 \mathrm{mg}$ of LOS, $5 \mathrm{mg}$ of AML, and $12.5 \mathrm{mg}$ of $\mathrm{HCZ}$ was transferred to a $50 \mathrm{~mL}$ volumetric flask. After addition of $30 \mathrm{~mL}$ of methanol and sonication ( $30 \mathrm{~min})$, the solution was diluted to volume with the same solvent and filtered through a $0.45 \mu$ filter (Millipore, Milford, MA, USA). To this solution known amount of amlodipine standard $(20 \mathrm{mg})$ was added (standard addition method) as its content is very low in the formulation. This solution $(1.0,2.0$, and $3.0 \mu \mathrm{L}$ containing 1000, 2000, and $3000 \mathrm{ng} / \mathrm{spot}$ of LOS, 500, 1000, and $1500 \mathrm{ng} / \mathrm{spot}$ of AML, and 250, 500, and $750 \mathrm{ng} / \mathrm{spot}$ of HCZ) was used for assay of losartan potassium, amlodipine, and hydrochlorothiazide in the tablets.

2.3. Chromatography. Chromatography was performed on $10 \mathrm{~cm} \times 10 \mathrm{~cm}$ aluminium HPTLC plates coated with $0.2 \mathrm{~mm}$ layers of silica gel $60 \mathrm{~F}_{254}$ (Merck). Samples were applied as $6 \mathrm{~mm}$ bands by means of a CAMAG (Muttenz Switzerland) Linomat $\mathrm{V}$ automatic sample applicator equipped with a
TABLE 2: Results from evaluation of precision.

\begin{tabular}{lccc}
\hline \multirow{2}{*}{ Drug } & $\begin{array}{c}\text { Concentration } \\
\text { (ng per spot) }\end{array}$ & $\begin{array}{c}\text { Intraday } \\
\text { precision } \\
(\mathrm{CV}, \%, \\
n=3)\end{array}$ & $\begin{array}{c}\text { Interday } \\
\text { precision } \\
(\mathrm{CV}, \%, \\
n=3)\end{array}$ \\
\hline \multirow{3}{*}{ Losartan potassium } & 1000 & 0.345 & 0.386 \\
& 2000 & 0.523 & 0.563 \\
\hline \multirow{3}{*}{ Amlodipine besylate } & 5000 & 0.213 & 0.254 \\
\hline \multirow{3}{*}{ Hydrochlorothiazide } & 1000 & 0.324 & 0.382 \\
& 1500 & 0.651 & 0.685 \\
& 500 & 0.772 & 0.791 \\
\hline
\end{tabular}

$100 \mu \mathrm{L}$ syringe (Hamilton, Reno, Nevada, USA). The distance between the bands of $14.0 \mathrm{~mm}$ and the spraying rate of $50 \mathrm{nl}$ per second were maintained. Ascending development of the plate up to a distance of $85 \mathrm{~mm}$ was performed at $25 \pm 2^{\circ} \mathrm{C}$, with chloroform-methanol-acetone-formic acid $7.5: 1.3: 0.5: 0.03(v / v / v / v)$ as mobile phase. The development was carried out in a CAMAG twin-trough chamber previously saturated with mobile phase vapour for $20 \mathrm{~min}$. The average development time was $30 \mathrm{~min}$. Densitometric scanning at $254 \mathrm{~nm}$ was performed with a CAMAG TLC scanner 3 equipped with CAMAG Wincats software version 1.4.4 using deuterium light source. During scanning process, the slit dimensions were fixed at $4.00 \mathrm{~mm} \times 0.30 \mathrm{~mm}$.

\section{Results and Discussion}

3.1. Validation of the Method. The method was validated in accordance with ICH guidelines [35].

3.1.1. Linearity. Different aliquots of standard solution equivalent to $0.5-3 \mu \mathrm{g}$ of LOS, AML, and HCZ per band were applied on the precoated TLC plates. The plates were then developed, dried, and scanned as described above. Calibration plots were constructed by plotting peak areas against the corresponding concentration of drugs (ng per spot). For all three drugs, the detector response was found to be a linear function of amount in the range 500-3000 ng per spot. The correlation coefficients of all the three drugs were found to be 0.9988 for LOS, 0.9985 for AML, and 0.9990 for HCZ, respectively. The average linear regression equations were $Y=4571.56 X+416.48$ for LOS, $Y=3229.40 X+300.24$ for AML, and $Y=5917.03 X+422.70$ for HCZ.

3.1.2. Sensitivity. The sensitivity of measurement of LOS, AML, and HCZ was estimated in terms of the limit of quantitation (LOQ). The smallest amount of each drug was also detected under the chromatographic conditions in terms of the limit of detection (LOD). LOQ and LOD were calculated by use of the equations LOD $=3 \times N / B$ and $\mathrm{LOQ}=10 \times N / B$, where $N$ is the standard deviation of the 
TABLE 3: Results from recovery studies.

\begin{tabular}{|c|c|c|c|c|c|c|}
\hline Brand name & Drug & Recovery level (\%) & Initial amount (ng) & Amount added (ng) & Recovery (\%) & $\mathrm{CV}(\%)$ \\
\hline \multirow{9}{*}{ Trilopace* $\mathrm{H}$} & \multirow{3}{*}{ Losartan potassium (50 mg) } & 80 & 2000 & 1600 & 100.56 & 0.213 \\
\hline & & 100 & 2000 & 2000 & 99.43 & 0.321 \\
\hline & & 120 & 2000 & 2400 & 99.67 & 0.422 \\
\hline & \multirow{3}{*}{ Amlodipine besylate ( $5 \mathrm{mg}$ ) } & 80 & 200 & 160 & 100.58 & 0.616 \\
\hline & & 100 & 200 & 200 & 101.12 & 0.222 \\
\hline & & 120 & 200 & 240 & 99.85 & 0.414 \\
\hline & \multirow{3}{*}{ Hydrochlorothiazide (12.5 mg) } & 80 & 500 & 400 & 99.43 & 0.552 \\
\hline & & 100 & 500 & 500 & 99.21 & 0.608 \\
\hline & & 120 & 500 & 600 & 100.63 & 0.621 \\
\hline
\end{tabular}

peak areas of the drugs, taken as a measure of the noise and $B$ is the slope of the corresponding calibration plot. LOQ and LOD for losartan potassium were found to be 0.382 and $0.121 \mu \mathrm{g} / \mathrm{spot}$, respectively. For amlodipine they were 0.584 and $0.188 \mu \mathrm{g} / \mathrm{spot}$, respectively, and for hydrochlorothiazide they were 0.497 and $0.162 \mu \mathrm{g} / \mathrm{spot}$, respectively.

\subsection{Evaluation of Precision for Assay of the Pharmaceutical} Preparation. The amount of losartan potassium, amlodipine, and hydrochlorothiazide in the pharmaceutical preparation were determined by replicate analysis $(n=3)$. The results are reported in Table 1.

Precision was determined by analysis of standard solutions containing concentrations of LOS, AML, and HCZ covering the entire calibration range. The precision of the method as intraday variation $(\mathrm{CV}, \%)$ was determined by analysis of these solutions three times on the same day. Interday precision $(\mathrm{CV}, \%)$ was assessed by analysis of these solutions on three different days over a period of one week. The results of the precision studies are shown in Table 2.

3.2.1. Accuracy. An accuracy of the method was determined by analysis of standard additions at three different levels, that is, multiple-level recovery studies. The preanalyzed sample solution (2, 0.5 , and $0.2 \mu \mathrm{g} / \mathrm{mL}$ of LOS, HCZ, and AML) was spiked with amounts equivalent to 80,100 , and $120 \%$ of standard drugs. These solutions were reanalysed, and the recoveries were found to be within the acceptable limits (Table 3).

3.2.2. Specificity. The mobile phase used was found to be effective in resolving the drugs (Figure 1). The $R_{F}$ values of losartan potassium, amlodipine, and hydrochlorothiazide were $0.74,0.35$, and 0.57 , respectively. Typical overlaid absorption spectra of LOS, AML, and HCZ is shown in Figure 2. Peak purity of the drugs was tested by acquiring spectra at the peak start $(S)$, peak apex $(A)$, and peak end $(E)$ positions. Results from correlation of the spectra were for losartan potassium $r(S, M)=0.9996$ and $r(M, E)=0.9994$, for amlodipine $r(S, M)=0.9994$ and $r(M, E)=0.9996$, and for hydrochlorothiazide $r(S, M)=0.9998$ and $r(M, E)=$ 0.9997 . The results of peak purity ensure the specificity and

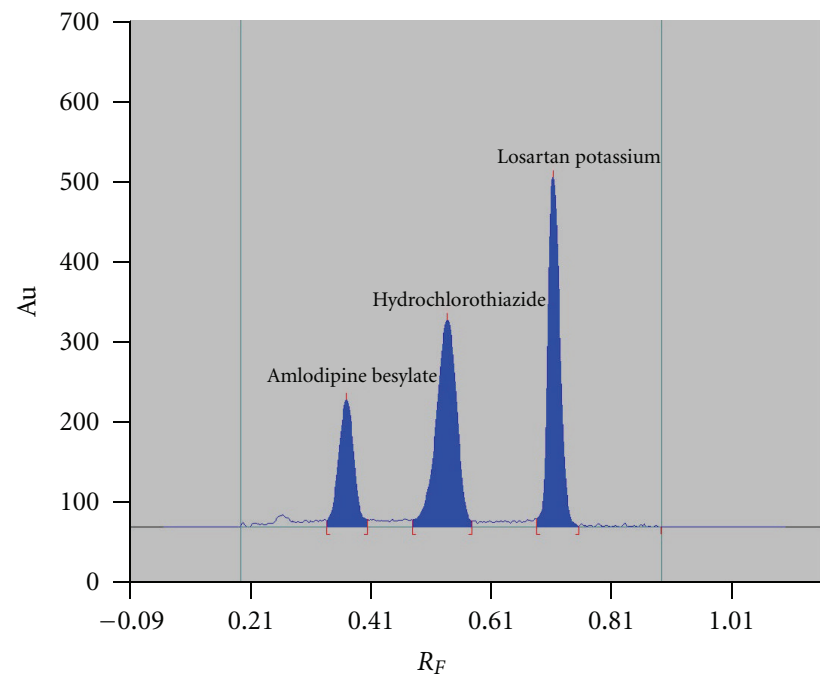

FIGURE 1: Typical densitogram obtained from losartan potassium $\left(R_{F}=0.74\right)$, amlodipine besylate $\left(R_{F}=0.35\right)$, and hydrochlorothiazide $\left(R_{F}=0.57\right)$. Detection was at $254 \mathrm{~nm}$ and the mobile phase was chloroform : methanol: acetone : formic acid $7.5: 1.3: 0.5: 0.03$ $(v / v / v / v)$.

can conclude that no impurities or degradation products were coeluted.

3.2.3. Repeatability. The repeatability of sample preparation was assessed by application of $2 \mu \mathrm{L}$ standard drug solution six times on a HPTLC plate. After development of plate, peak height and peak area were recorded for the zones. The CV (\%) of peak height and area were calculated and found to be 0.45 and 0.56 , respectively, for LOS, 0.34 and 0.43 for AML, and 0.67 and 0.32 for HCZ.

\section{Conclusion}

The proposed HPTLC method for simultaneous analysis of losartan potassium, amlodipine, and hydrochlorothiazide in pharmaceutical dosage forms has been established for the first time. Use of HPTLC enables analysis of several samples 


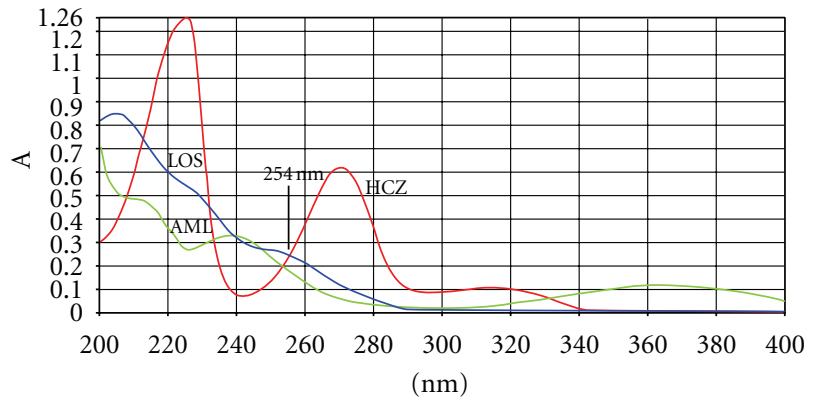

Figure 2: Typical absorption spectra of losartan potassium, amlodipine besylate, and hydrochlorothiazide.

at the same time. The method is very simple, rapid, and provides accurate and precise results.

\section{Acknowledgments}

The authors express their gratitude to the Madras Pharmaceuticals Ltd, Chennai, for the generous gifts of pure samples of losartan potassium, amlodipine besylate, and hydrochlorothiazide. The authors thank the management for providing the facilities to carry out the work.

\section{References}

[1] US Pharmacopeial Convention, US Pharmacopoeia, US Pharmacopeial convention, Rockville, Md, USA, 29th edition, 2007.

[2] HMSO, British Pharmacopoeia, International Edition, vol. 1, HMSO, Cambridge, UK, 2007.

[3] Government of India, Indian Pharmacopoeia, Government of India, Ministry of Health and Family Welfare, Delhi, India, 1996.

[4] M. D. R. Brunetto, Y. Contreras, S. Clavijo et al., "Determination of losartan, telmisartan, and valsartan by direct injection of human urine into a column-switching liquid chromatographic system with fluorescence detection," Journal of Pharmaceutical and Biomedical Analysis, vol. 50, no. 2, pp. 194-199, 2009.

[5] A. B. Thomas, M. R. Patankar, K. R. Deshmukh et al., "Simultaneous determination of losartan potassium and atenolol in tablet dosage form," Indian Drugs, vol. 44, no. 10, pp. 745-750, 2007.

[6] S. R. Sathe and S. B. Bari, "Simultaneous analysis of losartan potassium, atenolol, and hydrochlorothiazide in bulk and in tablets by high-performance thin-layer chromatography with UV absorption densitometry," Acta Chromatographica, no. 19, pp. 270-278, 2007.

[7] O. C. Lastra, I. G. Lemus, H. J. Sánchez, and R. F. Pérez, "Development and validation of an UV derivative spectrophotometric determination of Losartan potassium in tablets," Journal of Pharmaceutical and Biomedical Analysis, vol. 33, no. 2, pp. 175-180, 2003.

[8] M. B. Shankar, F. A. Mehta, K. K. Bhatt, R. S. Mehta, and M. Geetha, "Simultaneous spectrophotometric determination of losartan potassium and hydrochlorothiazide in tablets," Indian Journal of Pharmaceutical Sciences, vol. 65, no. 2, pp. 167-170, 2003.
[9] A. H. Prabhakar and R. Giridhar, "A rapid colorimetric method for the determination of Losartan potassium in bulk and in synthetic mixture for solid dosage form," Journal of Pharmaceutical and Biomedical Analysis, vol. 27, no. 6, pp. 861-866, 2002.

[10] D. L. Hertzog, J. F. McCafferty, X. Fang, R. J. Tyrrell, and R. A. Reed, "Development and validation of a stability-indicating HPLC method for the simultaneous determination of Losartan potassium, hydrochlorothiazide, and their degradation products," Journal of Pharmaceutical and Biomedical Analysis, vol. 30, no. 3, pp. 747-760, 2002.

[11] N. Erk, "Analysis of binary mixtures of losartan potassium and hydrochlorothiazide by using high performance liquid chromatography, ratio derivative spectrophotometric and compensation technique," Journal of Pharmaceutical and Biomedical Analysis, vol. 24, no. 4, pp. 603-611, 2001.

[12] E. Cagigal, L. González, R. M. Alonso, and R. M. Jiménez, "Experimental design methodologies to optimise the spectrofluorimetric determination of Losartan and Valsartan in human urine," Talanta, vol. 54, no. 6, pp. 1121-1133, 2001.

[13] G. Carlucci, G. Palumbo, P. Mazzeo, and M. Giovanna Quaglia, "Simultaneous determination of losartan and hydrochlorothiazide in tablets by high-performance liquid chromatography," Journal of Pharmaceutical and Biomedical Analysis, vol. 23, no. 1, pp. 185-189, 2000.

[14] D. Farthing, D. Sica, I. Fakhry, A. Pedro, and T. W. B. Gehr, "Simple high-performance liquid chromatographic method for determination of losartan and E-3174 metabolite in human plasma, urine and dialysate," Journal of Chromatography B, vol. 704, no. 1-2, pp. 374-378, 1997.

[15] N. V. V. S. S. Raman, K. R. Reddy, A. V. S. S. Prasad, and K. Ramakrishna, "Development and validation of RP-HPLC method for the determination of genotoxic alkyl benzenesulfonates in amlodipine besylate," Journal of Pharmaceutical and Biomedical Analysis, vol. 48, no. 1, pp. 227-230, 2008.

[16] V. G. Dongre, S. B. Shah, P. P. Karmuse, M. Phadke, and V. K. Jadhav, "Simultaneous determination of metoprolol succinate and amlodipine besylate in pharmaceutical dosage form by HPLC," Journal of Pharmaceutical and Biomedical Analysis, vol. 46, no. 3, pp. 583-586, 2008.

[17] L. R. Bhat, A. T. Vora, R. K. Godge, and M. C. Damle, "Simultaneous estimation of nebivolol hydrochloride and amlodipine besylate in bulk and tablet dosage form by ultraviolet spectrometry," Indian Drugs, vol. 44, no. 12, pp. 915-919, 2007.

[18] Y. Ma, F. Qin, X. Sun, X. Lu, and F. Li, "Determination and pharmacokinetic study of amlodipine in human plasma by ultra performance liquid chromatography-electrospray ionization mass spectrometry," Journal of Pharmaceutical and Biomedical Analysis, vol. 43, no. 4, pp. 1540-1545, 2007.

[19] A. V. Kasture and M. Ramteke, "Simultaneous UVspectrophotometric method for the estimation of atenolol and amlodipine besylate in combined dosage form," Indian Journal of Pharmaceutical Sciences, vol. 68, no. 3, pp. 394-396, 2006.

[20] D. A. Shah, K. K. Bhatt, M. B. Shankar, R. S. Mehta, T. R. Gandhi, and S. L. Baldania, "RP-HPLC determination of atorvastatin calcium and amlodipine besylate combination in tablets," Indian Journal of Pharmaceutical Sciences, vol. 68, no. 6, pp. 796-799, 2006.

[21] A. Zarghi, S. M. Foroutan, A. Shafaati, and A. Khoddam, "Validated HPLC method for determination of amlodipine in human plasma and its application to pharmacokinetic studies," Farmaco, vol. 60, no. 9, pp. 789-792, 2005. 
[22] K. R. Naidu, U. N. Kale, and M. S. Shingare, "Stability indicating RP-HPLC method for simultaneous determination of amlodipine and benazepril hydrochloride from their combination drug product," Journal of Pharmaceutical and Biomedical Analysis, vol. 39, no. 1-2, pp. 147-155, 2005.

[23] R. Klinkenberg, B. Streel, and A. Ceccato, "Development and validation of a liquid chromatographic method for the determination of amlodipine residues on manufacturing equipment surfaces," Journal of Pharmaceutical and Biomedical Analysis, vol. 32, no. 2, pp. 345-352, 2003.

[24] M. Josefsson and B. Norlander, "Coupled-column chromatography on a Chiral-AGP phase for determination of amlodipine enantiomers in human plasma: an HPLC assay with electrochemical detection," Journal of Pharmaceutical and Biomedical Analysis, vol. 15, no. 2, pp. 267-277, 1996.

[25] S. S. Chitalange, B. A. Agarval, D. M. Sakarkar, S. B. Wankhede, and R. K. Nanda, "Estimation of hydrochlorothiazide and valsartan in bulk and tablet dosage form by simultaneous equation method," Journal of Pharmaceutical Research, vol. 6, no. 4, pp. 208-209, 2007.

[26] E. Dinc, O. Ustundag, and I. L. Farmaco, "Spectophotometric quantitative resolution of hydrochlorothiazide and spironolactone in tablets by chemometric analysis methods," Farmaco, vol. 58, no. 11, pp. 1151-1161, 2003.

[27] L. J. Patel, B. N. Suhagia, P. B. Shah, and R. R. Shah, "Simultaneous estimation of bisoprolol fumarate and hydrochlorothiazide in tablet dosage form by RP-HPLC method," Indian Journal of Pharmaceutical Sciences, vol. 68, no. 5, pp. 635-638, 2006.

[28] T. Huang, Z. He, B. Yang, L. Shao, X. Zheng, and G. Duan, "Simultaneous determination of captopril and hydrochlorothiazide in human plasma by reverse-phase HPLC from linear gradient elution," Journal of Pharmaceutical and Biomedical Analysis, vol. 41, no. 2, pp. 644-648, 2006.

[29] E. Dinc and O. Ustundag, "Chemometric resolution of a mixture containing hydrochlorothiazide and amiloride by absorption and derivative spectrophotometry," Journal of Pharmaceutical and Biomedical Analysis, vol. 29, pp. 371-379, 2002.

[30] E. Dinc and D. Baleanu, "Spectrophotometric quantitative determination of cilazapril and hydrochlorothiazide in tablets by chemometric methods," Journal of Pharmaceutical and Biomedical Analysis, vol. 30, no. 3, pp. 715-723, 2002.

[31] A. El-Gindy, A. Ashour, L. Abdel-Fattah, and M. M. Shabana, "Spectrophotometric and HPTLC-densitometric determination of lisinopril and hydrochlorothiazide in binary mixtures," Journal of Pharmaceutical and Biomedical Analysis, vol. 25, no. 5-6, pp. 923-931, 2001.

[32] A. El-Gindy, A. Ashour, L. Abdel-Fattah, and M. M. Shabana, "Spectrophotometric determination of benazepril hydrochloride and hydrochlorothiazide in binary mixture using second derivative, second derivative of the ratio spectra and chemometric methods," Journal of Pharmaceutical and Biomedical Analysis, vol. 25, no. 2, pp. 299-307, 2001.

[33] M. Zecevic, L. J. Zivanovic, S. Agatonovic-Kustrin, D. Ivanovic, and M. Maksimovic, "Statistical optimization of a reversed-phase liquid chromatographic method for the analysis of amiloride and hydrochlorothiazide in tablets," Journal of Pharmaceutical and Biomedical Analysis, vol. 22, no. 1, pp. 1-6, 2000.

[34] I. E. Panderi, "Simultaneous determination of benazepril hydrochloride and hydrochlorothiazide in tablets by secondorder derivative spectrophotometry," Journal of Pharmaceutical and Biomedical Analysis, vol. 21, no. 2, pp. 257-265, 1999.
[35] ICH Guidelines Q2B, Validation of Analytical ProceduresMethodology, 1996. 


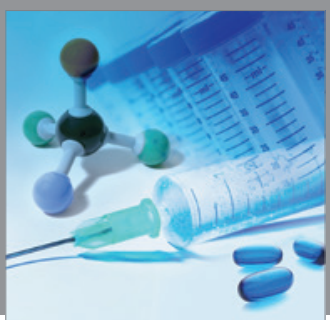

International Journal of

Medicinal Chemistry

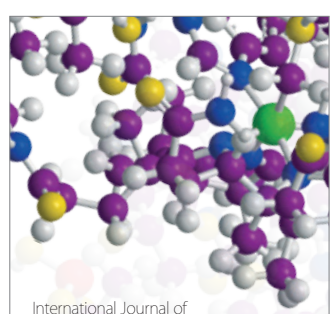

Carbohydrate Chemistry

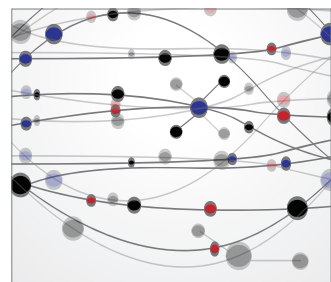

The Scientific World Journal
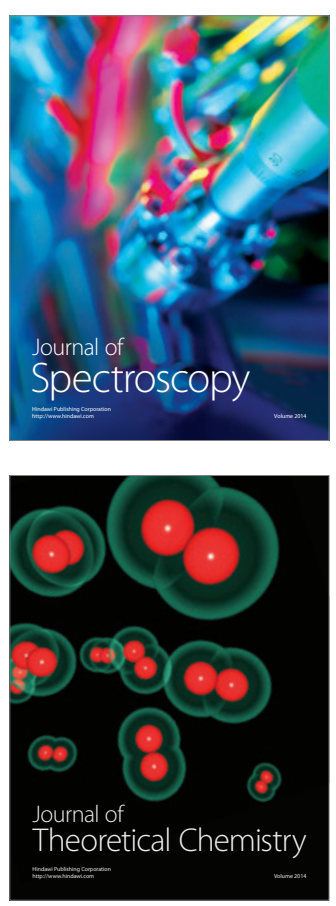
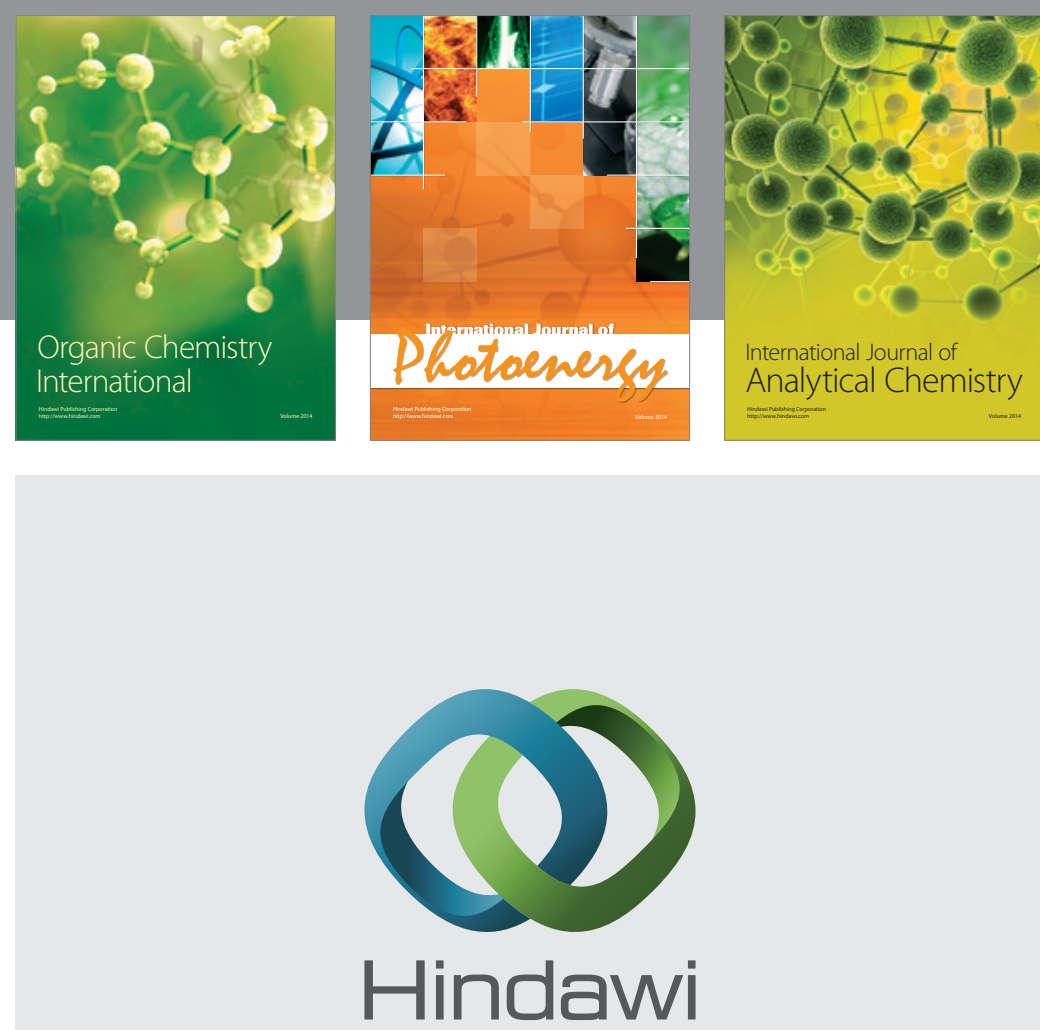

Submit your manuscripts at

http://www.hindawi.com
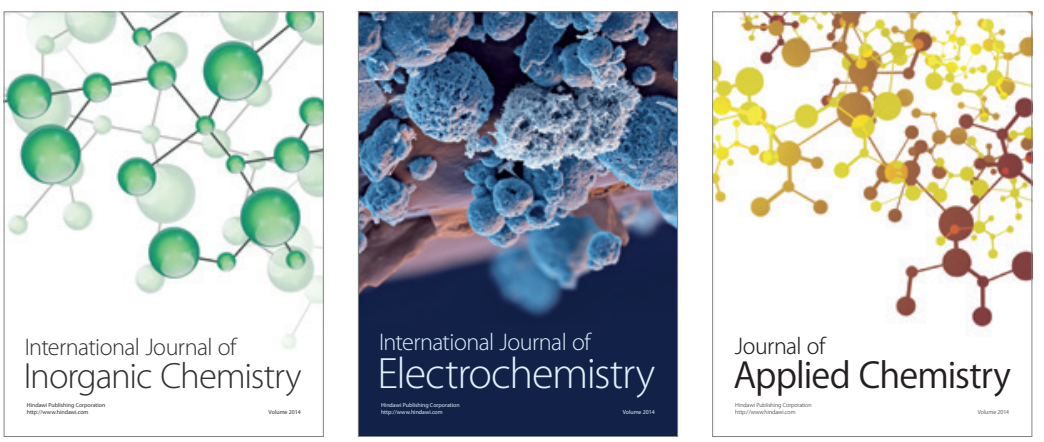

Journal of

Applied Chemistry
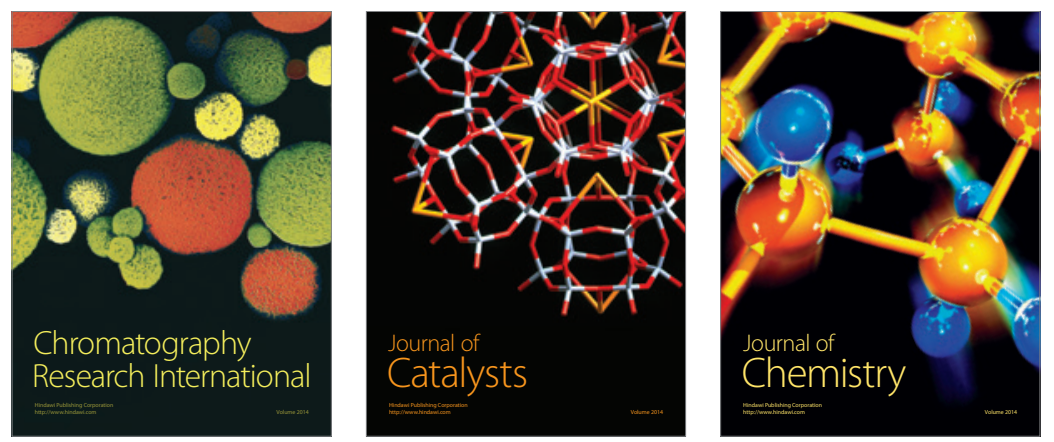
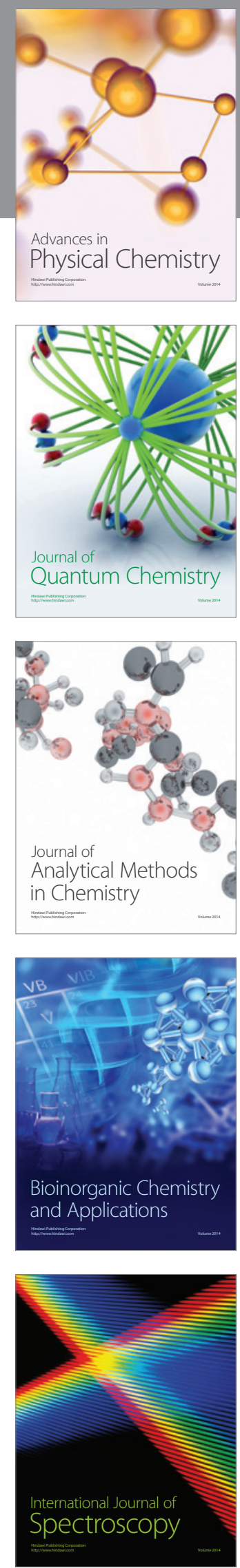